\title{
TEACHER-PUPIL RELATIONSHIPS AND SCHOOL ADJUSTMENT THE ATTACHMENT LENS AND THE DYADIC EXPANSION OF CONSCIOUSNESS APPROACH
}

\author{
Oana Dănilă, \& Alina Terente \\ Faculty of Psychology and Educational Sciences, Alexandru Ioan Cuza University (Romania)
}

\begin{abstract}
The purpose of this study was to explore the connection between the quality of the pupil-teacher relationship, assessed from the attachment perspective and different school adjustment aspects. A sample of 40 educators were invited to evaluate their attachment strategies and then assess at least 3 children from their current classes (primary school); results for a total of 121 pupils were collected. First of all, educators assessed the pupil's attachment needs using the Student-Teacher Relationship Scale (Koomen, Verschueren, van Schooten, Jak, \& Pianta, 2012); then, they were asked to assess social competencies using the Social Competence Scale (Corrigan, 2014) and the Engagement versus Disaffection with Learning Scale (Skinner, Kindermann, \& Furrer, 2009), as facets of school adjustment. Results show that the strength of the pupil-teacher relationship is influenced by the particularities of the attachment strategies of both parties, and, in turn, this relationship, with its 3 dimensions (closeness, conflict and dependence) impacts adjustment. Results are discussed in the light of the Dyadic Expansion of Consciousness hypothesis - in a safe relationship, both the teacher and the pupil significantly expand the learning possibilities.
\end{abstract}

Keywords: Attachment strategies, school adjustment, dyadic expansion of consciousness.

\section{Introduction}

Initially introduced by John Bowlby, the concept of attachment refers to an inherited system that is meant to insure survival in the psychological sense of the term. Bowlby (1973) unpacks the activation process of this system and suggests that interactions with significant others, particularly in moments of danger, are internalized in two specific mental models: the self-image and the image of others (the attachment models), that in turn organize cognitions, affects and social behaviors throughout our entire lives. What is the underlying mechanism? When attachment figures (primary caregivers) are perceived as available and ready to attend to the needs of the individual, in response, the child (and later in life, the adult) develops a sense of being secure in his/ her close relationships when perceived absent or lacking reaction, the same attachment figures can induce a terrible sense of insecurity (Mikulincer and Shaver, 2007). This experience of security/ insecurity is integrated in the internal working models of the individual, the self-image and the image of the others: if cared for and needs met, one feels worthy of love and belonging and can trust others to come when in need; as already stated above, these models influence cognitions, experiences and the capacity for emotional regulation, the expression of the need for closeness and various other behaviors, all across the life span (Collins, Guichard, Ford, and Feeney, 2004; Mikulincer, Shaver, Pereg, 2003).

The second major concept of this paper poses a challenge when to be defined; adjusting to school/ educational system has been differently measured and described in time. We consider the perspective of Ladd (1990) and Perry \& Weinstein (1998) that broaden the definition to encompass the degree to which a child becomes interested, engaged, comfortable and successful in his education environment (Buyse, Verschueren, Verachtert, \& Van Damme, 2009). As such, one needs to look at the reality of adjusting considering a variety of aspects, amongst which the age will be linked to the strength of the protective systems of the child. In the first years of educational exposure, the adjustment refers to the extent to which preschoolers develop positive versus negative perception in regards to education, are comfortable or not in the classrooms, get involved or not in the tasks and other activities (Buyse, Verschueren, Verachtert, \& Van Damme, 2009; Ladd, 1990). Therefore, Ladd's model places a great value on relationship inbetween the child's characteristics and the support he gets from his main 
connection sources, but as well the stressors coming from all context: family, educational system, community. This is why we embrace a perspective of the school adjustment as a complex process, with multiple facets, reflecting first of all (as the most traditional models were showing) the adjustment to academic requests, but adding as well the adjustment to socio-emotional tasks and other behavioral challenges, that in turn lead to the development of specific competencies that will be used and improved throughout the entire educational path (Perry \& Weinstein, 1998; Magelinskaite-Legkauskienè, Legkauskas, \& Kepalaitè, 2018).

As such, our view is that when entering the educational system children bring in their backpacks their attachment system as well. Collins and Sroufe (1999) are the authors of a transactional model whereby they underline that the early attachment experiences continue to affect children's functioning and all others relationships, while children also contribute to their own development and environments by responding and engaging with others relying on the previous patterns of adaptation and expectations. As such, various children might experience safety for the very first time in the relationship with the educators as different background factors impeded their caregivers to offer them a safe upbringing environment. Adjusting to the school environment is a task of great novelty and challenge so the activation of the attachments system is a given from the very beginning. And yet researchers are not convinced that one should consider educators attachment figure as well. Verschueren (2015) believes that the teacher-pupil relationship cannot become an attachment in the true sense of the concept for all children due to the lack of exclusivity and sustainability, the differences in potential emotional investment teachers can make as compared to the parents. Unfortunately, this unanimous view translates into problems for all parties, children, caregivers and educators, especially when insecurity is the" key word". Insecurity can activate 2 different directions:

a. anxiously seeking the proximity of an attachment figure and asking for comfort or

b. persistent avoidance/ keeping away, both physical and mentally, as the sole solution to minimize the exposure to situations where one could feel helpless, extremely lonely or hurt.

So, what are the difference? Research shows that preschoolers who are securely attached to their mothers are more socially competent and thus adapt easier, they become leaders in peer groups, have more positive interactions with elders, are more empathetic, more popular, cooperate better, and are evaluated by educators as having a higher level of social skills (Copeland-Mitchell, Denham, \& DeMuler, 1997). How about the insecure ones? Children with an avoidant attachment have poorer vocabulary, limited creativity, demonstrate hostility toward the teacher and school tasks, and deny the need for help (Geddes, 2018). Sroufe (apud Pianta, Steinberg and Rollins, 1995) argues that pupils with histories of anxious / avoided attachment make less contact with teachers, and teachers often react mostly with fury to these children. Children with an ambivalent or resistant attachment style are prone to absenteeism, tend to develop teacher addiction behaviors, have good verbal skills that can be used to dominate and manipulate the teacher's attention and experience a constant fear of losing the educator's attention (Geddes, 2018). In general, they are perceived by teachers as vulnerable and fragile (Sroufe apud Pianta, Steinberg and Rollins, 1995). Spilt and Koomen (2009), combining a qualitative and quantitative study approach delineate several interesting findings: when teachers evaluate relationships as not to close to their pupils, they evoke feelings of ineffectiveness and that they are discouraged to invest in the child or find themselves searching for new strategies to assert influence; as well, teachers expressed more anger and helplessness concerning children they asses as more disruptive in their class as compared to a nondisruptive child.

Talking about attachment in the context of teaching, Cozolino (2017, p. 65) pinpoints: "The brain has been designed to develop when stimulated. In other words, the brain lives for the sole purpose of learning. This impulse is nurtured when rewarded by persons that are fully carrying. If not properly rewarded or even punished for curiosity, the brain learns to hide, avoid risks and resume to what is familiar. Even if every child is capable to learn, some children have brains, minds and souls that have been shut down". Using Cozolino's lens we argue that teacher-pupil relationships are key factors in strengthening internal working models of the child; adding the Dyadic Expansion of Consciousness Hypothesis (Tronick at al, 1998) we consider that the process is reflecting back on the teacher as well. Relying as well on the theory of attachment, the Dyadic Expansion of Consciousness Hypothesis adds beautifully to Cozolino's view when stating that "... each individual is a self-organizing system that creates its own states of consciousness-states of brain organization-which can be expanded into more coherent and complex states in collaboration with another self-organizing system. When the collaboration of two brains is successful each fulfills the system principle of increasing their coherence and complexity (Tronick at all, 1998, p. 296)."

Integrating these lenses, it is our goal to test the impact of the teacher- pupil similarity in terms of attachment characteristics upon the different facets of school adjustment as assessed by the teacher. 


\section{Method}

\subsection{Participants}

The sample consisted of 121 educator-pupil pairs. The educators' sample comprised 40 experienced, female graduate-level educators with at least 3 or more years of teaching experience (20.5 mean of teaching experience): ten 1 st grade teachers, ten 2 nd grade teachers, eleven 3rd grade teachers, nine 4th grade teachers. The sample of children comprised 121 pupils (mean age $=9.52, \mathrm{SD}=1.7$ ), 30 in the first grade, 29 in the 2 nd grade, 31 in $3 \mathrm{rd}, 31$ in 4 th, 51,2 \% males and 48.7\% females. The sample was recruited from schools in a mid-low-socio-economic status area in north-east Romania. Parental permission was obtained for participation.

\subsection{Measures}

Student-Teacher Relationship Scale (Koomen, Verschueren, van Schooten, Jak, \& Pianta, 2012) as one of the most used instrument to assess the strength of the attachment relationship of teachers and pupils includes 32 items divided over three scales: Conflict (11 items), Closeness (14 items), and Dependency ( 7 items). Cronbach's $\alpha$ coefficients from .67 to .84 indicated respectable to very good reliability according to the standards for research. Next, teachers self-rated their attachment style using the Relationship Structures (ECR-RS) (Fraley, 2011). The test includes 9 items that can refer to different relationships and has a Cronbach's $\alpha$ coefficient .81 .

Educators were asked to assess pupils' social competencies as well using the Social Competence Scale (Corrigan, 2014) and the Engagement versus Disaffection with Learning Scale (Skinner, Kindermann, \& Furrer, 2009), as facets of school adjustment. Developed ever since 2003, the Social Competence Scale includes 25 items that refer to the prosocial behavior (8 items), emotional self- regulation (10 items) and the academic abilities of a child (7 items). Cronbach's $\alpha$ coefficients from .92 to .94 indicate very good reliability according to the standards for research. The Engagement versus Disaffection with Learning Scale is compromised out of 32 items as well divided into different subscales, such as behavioral engagement, emotional engagement, emotional lack of involvement and re-engagement. Cronbach's $\alpha$ coefficients are as well according to the standards for research from .80 to .94 indicated respectable to very good reliability.

\section{Results}

\subsection{Educator-pupil attachment-like relationships: A person-centered approach}

O'Connor et al. (2012) emphasized the significance of a person-centered approach to the comprehension of an educator-pupil relationship. Cluster analysis has been suggested as a useful method for classifying patterns or profiles in a sample. The silhouette measure of cohesion and separation for cluster quality is a measure of the overall goodness-of-fit of the clustering solution. It is based on the average distance between the objects, and can vary between -1 and +1 . A silhouette measure of less than 0.20 indicates a poor solution quality, one between 0.20 and 0.50 a fair solution, while values of more than 0.50 indicate a good solution. In our study, Two-Step cluster analysis yielded a two-group solution. The silhouette measure of cohesion and separation for cluster quality showed fair (0.4) overall goodness-of-fit, indicating that two groups are statistically the optimal number-of-clusters solution. The two-cluster solution distribution also corresponds to the theoretical typology regarding schoolchildren's secure and insecure attachment styles.

Table 1. Cluster analysis for teacher-student attachment-like variables.

TEACHER SELF-RATED ATTACHMENT STYLE

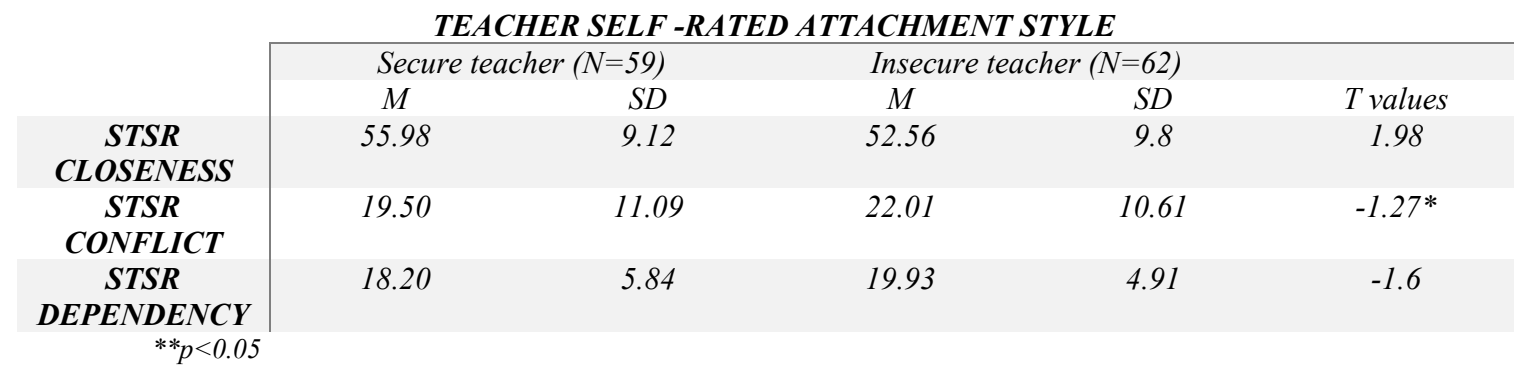


The first group $(n=59,48.8 \%)$ was labeled secure educator - pupil attachment-like style. The group is characterized by higher levels of perceived closeness, lower levels of conflict and dependency. The second group $(n=62,51.2 \%)$ was labeled insecure educator - pupil attachment-like style. The group is characterized by lower levels of perceived closeness, higher levels of conflict and dependency. Conflict is the sole dimension with significant differences.

\subsection{Differences between pupils having secure educator -pupil attachment-like style and those having insecure educator -pupil attachment-like style in school adjustment}

T-tests analyses, conducted to assess whether pupils having secure attachment-like relationships with their educators and those having insecure attachment-like relationships with their educators differed with regard to their social competencies and learning engagement, as facets of school adjustment, were found to be significant for most of the subscales.

Table 2. T-test for the differences between the secure and the insecure educator-pupil attachment-like style groups in school adjustment variables.

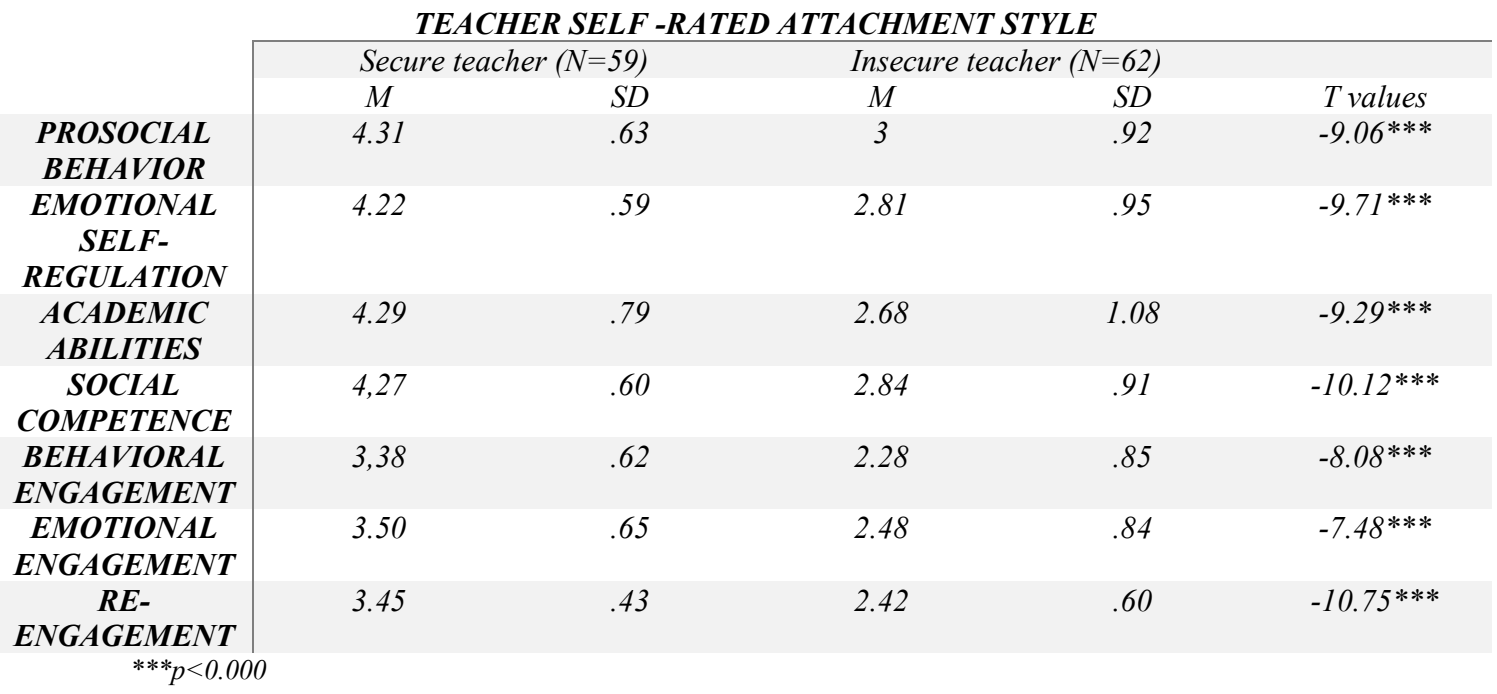

As shown in Table 2, children with secure attachment-like relationships with their educators showed a higher tendency towards prosocial behaviors, can easier self-regulate, have overall better academic abilities, tend to get involved behaviorally and emotionally, and can as well re-engage after a context where he or she is prone to disengage.

\section{Discussion}

When attuned and safe together, the educator and the pupil enter a synergy that creates the platform of development for both. The interaction between the teacher, the pupil and the learning task is a continuous dynamic where the task should be built on the teacher's awareness and understanding of the pupil, while the pupil can seek reliable support when challenged by the task. Each relates to the other in a specific way that should fosters curiosity; there is little space for learning, exploring and keeping curious if one is not helped to regulate the emotions uncertainty that can created. Paradoxically, the challenges of 'not knowing' are at the heart of all learning (Geddes 2006), while being in the very safe time the triggers of insecurity. As a stronger and wiser, self- regulated adult, the educator helps the child with the regulation and allows himself to be challenged by the brain that I still forming.

Limitations are not to be ignored especially if one considers generalizing the results; the rather small sample, the fact that there are only female teachers, the fact that educators are the only ones to assess the child and this can create biases are amongst the aspects that need to be properly controlled in a future study expanding the current one. Nevertheless, the combination of the two-explanatory lens, attachment and Dyadic Expansion of Consciousness remains the element of novelty that we believe will encourage researches in other education system to test the relationship as well. 


\section{References}

Al-Yagon, M., \& Mikulincer, M. (2004). Socioemotional and Academic Adjustment Among Children with Learning Disorders: The Mediational Role of Attachment-Based Factors. The Journal of Special Education, 30 (2), 111-123.

Bowlby, J. (1973). Separation: Anxiety \& Anger. Attachment and Loss (vol. 2); (International psycho-analytical library no.95). London: Hogarth Press

Collins, N. L., Guichard, A. C., Ford, M. B., \& Feeney, B. C. (2004). Working Models of Attachment: New Developments and Emerging Themes. In W. S. Rholes, \& J. A. Simpson (Eds.), Adult Attachment: Theory, Research, and Clinical Implications (pp. 196-239). New York, NY: The Guilford Press.

Collins, W. A., \& Sroufe, L. A. (1999). Capacity for intimate relationships: A developmental construction. In W. Furman, B. B. Brown, \& C. Feiring (Eds.), The development of romantic relationships in adolescence (pp. 125-147). New York: Cambridge University Press.

Copeland-Mitchell, J., Denham, S. A., \& DeMuler, E. K. (1997). Q-sort assessment of child-teacher attachment relationships and social competence in the preschool. Early Education and Development, 8, 27-39.

Cozolino, L. (2017). Predarea bazată pe ataşament, Bucuresti: Editura Trei

Fraley, R. C., Heffernan, M. E., Vicary, A. M., \& Brumbaugh, C. C. (2011). The Experiences in Close Relationships-Relationship Structures questionnaire: A method for assessing attachment orientations across relationships. Psychological Assessment, 23, 615-625.

Geddes, H. (2018) Attachment and learning - the links between early experiences and responses in the classroom. International Journal of Nurture in Education, 4(1), 15-21

Koomen, H. M., Verschueren, K., van Schooten, E., Jak, S., \& Pianta, R. C. (2012). Validating the Student-Teacher Relationship Scale: Testing factor structure and measurement invariance across child gender and age in a Dutch sample. Journal of School Psychology, 50, 215-234.

Ladd, G. W. (1990). Having Friends, Keeping Friends, Making Friends, and Being Liked by Peers in the Classroom: Predictors of Children's Early School Adjustment? Child development, 61, 1081-1100.

Magelinskaitè-Legkauskienė, Š., Legkauskas, V., \& Kepalaite, A. (2018). Teacher perceptions of student social competence and school adjustment in elementary school. Cogent Psychology, 5, 1421406.

Mikulincer, M., \& Shaver, P. R. (2007). Attachment in adulthood: Structure, dynamics, and change. New York, NY:Guilford Press.

Mikulincer, M., Shaver, P. R., \& Pereg, D. (2003). Attachment theory and affect regulation: The dynamics, development, and cognitive consequences of attachment-related strategies. Motivation and Emotion, 27(2), 77-102.

O'Connor, E. E., Collins, B. A. \& Supplee, L. (2012), Behavior problems in late childhood: the roles of early maternal attachment and teacher-child relationships trajectories. Attachment \& Human Development. Vol. 14, No. 3, 265-288.

Perry, K. E., \& Weinstein, R. S. (1998). The Social Context of Early Schooling and Children's School Adjustment. Educational Psychologist, 33 (4), 177-194.

Pianta, R. C., Steinberg, M. S., \& Rollins, K. B. (1995). The first two years of school: Teacher-child relationships and deflections in children's classroom adjustment. Development and Psychopathology, 7, 295-312.

Skinner, E. A., Kindermann, T. A., \& Furrer, C. J. (2009). A Motivational Perspective on Engagement and Disaffection: Conceptualization and Assessment of Children's Behavioral and Emotional Participation in Academic Activities in the Classroom. Educational and Psychological Measurement, 69 (3), 493-525.

Spilt, J. L., \& Koomen, H. M. Y. (2009). Widening the view on teacher-child relationships: teachers' narrativesconcerning disruptive versus nondisruptive children. School Psychology Review, 38(1), 86-101

Tronick, E. Z., Brushweiller-Stern, N., Harrison, A. M., Lyons-Ruth, K., Morgan, A. C., Nahum, J. P., et al. (1998). Dyadically expanded states of consciousness and the process of therapeutic change. Infant Mental Health Journal, 19, 290-299.

Verschueren, K. (2015). Middle Childhood Teacher-Child Relationship: Insights from an Attachment Perspective and Remaining Challenges. New Directions for Child and Adolescent Development, 148, 77-91. 